Research Article

\title{
Recycling Glass Cullet from Waste CRTs for the Production of High Strength Mortars
}

\author{
Stefano Maschio, Gabriele Tonello, and Erika Furlani \\ Dipartimento di Chimica, Università di Udine, Fisica e Ambiente, 108 Via del Cotonificio, 33100 Udine, Italy \\ Correspondence should be addressed to Erika Furlani; erika.furlani@uniud.it
}

Received 18 February 2013; Revised 8 May 2013; Accepted 15 May 2013

Academic Editor: Jay N. Meegoda

Copyright ( 2013 Stefano Maschio et al. This is an open access article distributed under the Creative Commons Attribution License, which permits unrestricted use, distribution, and reproduction in any medium, provided the original work is properly cited.

\begin{abstract}
The present paper reports on the results of some experiments dealing with the recycling of mixed cathode ray tube (CRT) glass waste in the production of high-strength mortars. Waste CRT glass cullet was previously milled, and sieved, and the only fine fraction was added to the fresh mortar in order to replace part of the natural aggregate. The addition of superplasticizer was also investigated. All hydrated materials displayed high compressive strength after curing. Samples containing CRT mixed glass showed a more rapid increase of strength with respect to the reference compositions, and materials with a superplasticizer content of $1 \%$ showed the best overall performance due to the favourable influence of the small glass particles which increase the amount of silicate hydrated produced. The induced coupled plasma (ICP) analysis made on the solutions, obtained from the leaching tests, confirmed the low elution of hazardous elements from the monolithic materials produced and consequently their possible environmental compatibility.
\end{abstract}

\section{Introduction}

CRT glass waste includes that from TVs, PC monitors and other monitors used in special applications, and waste from the original assembly process. Waste glass from PC and TV monitors will begin to decline as a direct consequence of the emerging flat screen display technology; nevertheless, it seems reasonable to assume that an amount of CRTs from all sources is likely to continue to enter into the waste stream in the coming years. Studies have shown that when CRTs are disposed of in landfill sites, leaching processes from the crushed glass cullet may contaminate ground water. This is a major driving force for CRT recycling. Moreover, it must be pointed out that CRT waste does not contain only glass but also other materials which concur with the CRTs assembly, such as ferrous and nonferrous metals and plastics. The Waste Electrical and Electronic Equipment (WEEE) directive sets strict regulations for recycling or recovery when materials derive from equipment containing CRTs. Such norms must obviously be coupled with those reported by the European Waste Catalogue which classifies CRTs as hazardous waste and makes landfill disposal of CRT materials costly. The great amount of CRT waste produced all over the world implies that its recycling is presently necessary not only due to the rising cost of landfill disposal, which is reflected on the cost of new CRTs produced, but also as a consequence of the "zero-waste" objective which must be the final goal of all future human activities. Mixed CRT glass (funnel, neck and screen glass) contains high amounts of $\mathrm{PbO}, \mathrm{BaO}$, and $\mathrm{SrO}$; it follows that cullet with this composition is unsuitable for recycling in applications where metal oxides could leach into food products or ground water. A possible partial recovery of waste CRT glass from the assembly process could follow the path of the manufacture of new CRTs, even if the high cost of separating, sorting, and processing the glass to meet the standards required by glass manufacturers strongly limits this option [1]. Other methods for waste CRT glass recycling are the copper-lead smelter where it acts as a substitute for sand in the smelting process [2] or as an additive raw material in the ceramic industry for the production of tiles or other monolithic ceramic materials $[3,4]$. The above options represent, however, a small number of opportunities for waste CRT glass recovery, and additional proposals are necessary in 
order to maximise its reuse in the production of other types of materials.

In order to propose a new option for waste CRT glass recycling, as independently as possible from glass composition, in the present research the production of stable mortars was carried out using cement, ground-waste-mixed CRT glass (funnel, neck, and screen glass), natural aggregate, and water; the addition of superplasticizer was also investigated. Mortars are expected to take advantage of ground glass; it is known, in fact, that the addition of silica fume as a component material in the production of mortars or concretes can lead to the preparation of products, namely, reaction powders mortars or concretes (RPM, RPC), with low water absorption, high mechanical properties, and modified shrinkage $[5,6]$. In a parallel approach, the addition of generic waste glass to mortars or concretes has been widely investigated [7, 8]. It has been demonstrated, for example, that the use of waste glass from crushed containers as concrete aggregate may develop pozzolanic activity which is affected by glass finenesses and chemical composition $[9,10]$. Such properties may also affect workability [11], strength, and durability. More in particular a high content of alkalis can cause alkali silica reaction (ASR) and expansion $[12,13]$. Conversely, the use of waste E-glass from electronic scraps (low-alkali content) improves compressive strength and sulphate resistance and reduces chloride-ion penetration with no adverse alkali silica reaction-expansion effects [14]. The addition of the specific CRT glass waste has been, on the other hand, recently studied [15-17]; however additional detailed studies are worthy of interest.

In the present research, mortars were produced using a fixed cement/aggregate (c/a) ratio (1/3), as it has been often proposed in the literature $[18,19]$, whereas milled CRT mixed glass was added in different proportions as well as were different contents of superplasticizer. The goal of the present research is to demonstrate that by selecting a proper amount of milled CRT waste glass coupled with an optimal quantity of superplasticizer, it is possible to produce mortars with high compressive strength, low water absorption, and therefore long durability coupled with low elution release of hazardous elements.

\section{Experimentals}

2.1. Materials. The starting materials used were: a type I ordinary portland cement (OPC) and a natural aggregate with maximum particle dimension of $4.76 \mathrm{~mm}$, Blaine fineness of $3480 \mathrm{~cm}^{2} \mathrm{~g}^{-1}$ (EN 933-2), density of $2.46 \mathrm{~g} \mathrm{~cm}^{-3}$, and water absorption of $0.37 \%$ (the measurement was carried out following the ASTM C127 and C128 norms) which were mixed with different proportions of mixed CRT waste glass. The as-received CRT glass cullet was first transformed into a powder by milling and then sieved by a $500 \mu \mathrm{m}$ sieve. Only the part of powdered glass with size smaller than $500 \mu \mathrm{m}$ was used for the present research; particles of larger dimensions were remilled. Glenium 51 (BASF) was also used as a superplasticizer in the preparation of some specimens. The required amount of water was obviously added to each
TABLE 1: Composition (oxide wt\%), organic carbon, specific gravity, LOI and fineness modulus of milled CRT mixed glass, cement and aggregate; "undetermined" indicates the cumulative quantity of all oxides determined in quantity lower than $0.1 \mathrm{wt} \%$.

\begin{tabular}{|c|c|c|c|}
\hline Component & CRT glass & Cement & Aggregate \\
\hline $\mathrm{SiO}_{2}$ & 59.74 & 21.40 & 1.98 \\
\hline $\mathrm{Al}_{2} \mathrm{O}_{3}$ & 2.67 & 1.48 & 1.72 \\
\hline $\mathrm{CaO}$ & 2.06 & 61.02 & 46.73 \\
\hline $\mathrm{MgO}$ & 1.15 & 1.16 & 19.83 \\
\hline $\mathrm{Na}_{2} \mathrm{O}$ & 6.81 & 0.26 & 1.43 \\
\hline $\mathrm{K}_{2} \mathrm{O}$ & 6.15 & 0.53 & 0.74 \\
\hline $\mathrm{Fe}_{2} \mathrm{O}_{3}$ & 0.11 & 0.35 & 2.1 \\
\hline $\mathrm{TiO}_{2}$ & 0.17 & $<0.1$ & $<0.1$ \\
\hline $\mathrm{CuO}$ & 0.21 & $<0.1$ & $<0.1$ \\
\hline $\mathrm{BaO}$ & 6.13 & $<0.1$ & $<0.1$ \\
\hline $\mathrm{SrO}$ & 4.77 & $<0.1$ & $<0.1$ \\
\hline $\mathrm{Sb}_{2} \mathrm{O}_{3}$ & 0.28 & $<0.1$ & $<0.1$ \\
\hline $\mathrm{ZrO}_{2}$ & 0.39 & $<0.1$ & $<0.1$ \\
\hline $\mathrm{PbO}$ & 8.33 & $<0.1$ & $<0.1$ \\
\hline $\mathrm{SO}_{4}=$ & 0.49 & 2.92 & 0.13 \\
\hline C (organic) & $<0.1$ & 1.20 & 0.57 \\
\hline Undetermined & 0.93 & 1.38 & 1.92 \\
\hline Density $\left(\mathrm{g} \mathrm{cm}^{-3}\right)$ & 2.95 & 3.03 & 2.46 \\
\hline Water abs. (\%) & 0.20 & - & 0.37 \\
\hline LOI (\%) & 0.82 & 13.14 & 23.55 \\
\hline Fineness modulus & 0.72 & - & 3.48 \\
\hline
\end{tabular}

starting blend. The chemical analysis of cement, natural aggregate, and CRT glass, determined by a Spectro Mass 2000 ICP mass spectrometer, is reported, in terms of oxides, in Table 1 which also displays loss on ignition (LOI), obtained after thermal treatment at $1000^{\circ} \mathrm{C}$ for $2 \mathrm{~h}$, density, water absorption, and Blaine fineness.

It is observed that CRT glass contains, together with an expected major quantity of $\mathrm{SiO}_{2}$, also great fractions of $\mathrm{PbO}$, $\mathrm{Na}_{2} \mathrm{O}, \mathrm{K}_{2} \mathrm{O}, \mathrm{BaO}, \mathrm{SrO}$, and moderate quantities of $\mathrm{Al}_{2} \mathrm{O}_{3}$, $\mathrm{CaO}$, and $\mathrm{MgO}$; other compounds as well as organic carbon are present in limited amounts so that also LOI is limited as is the water absorption. Aggregate mainly contains calcium and magnesium oxide accompanied by small fractions of silica, iron oxide, and alumina; organic carbon, density, and LOI are in line with the literature data $[5,20]$. The OPC conforms to European Standards EN-197/1. Data reported in Table 1 are confirmed by the XRD analysis of the starting materials (not reported in the present paper) which revealed the presence of alite $(84 \%)$ and belite $(16 \%)$ in cement, whereas dolomite $(65 \%)$, calcium carbonate $(27 \%)$, and free quartz $(8 \%)$ were identified in the aggregate; numbers must be read with caution since XRD analysis does not provide accurate quantitative analysis of the tested materials, but they only supply an approximate magnitude order of their crystallographic composition. It can be also observed that CRT glass has a density of 2.95, OPC 3.03, and aggregate $2.46 \mathrm{~g} \mathrm{~cm}^{-3}$. It is worth to point out the low Blaine fineness of the milled and sieved CRT glass (0.72), thus confirming 
the presence of a large fraction of particles with size below $75 \mu \mathrm{m}$ and therefore in agreement with the characteristics suggested by other authors [14] when the production of high-performance materials containing milled waste glass is required.

\subsection{Methods}

2.2.1. X-Ray Diffraction Investigation (XRD). The crystalline phases of starting components as well as those of the hydrated materials were investigated by X-ray diffraction (XRD). XRD patterns were recorded on a Philips X'Pert diffractometer operating at $40 \mathrm{kV}$ and $40 \mathrm{~mA}$ using Ni-filtered $\mathrm{Cu}-\mathrm{K}_{\alpha}$ radiation. Spectra were collected using a step size of $0.02^{\circ}$ and a counting time of $40 \mathrm{~s}$ per angular abscissa in the range of $15-55^{\circ}$. Philips X'Pert High Score software was used for phase identification and semiquantitative analysis (RIR method).

2.2.2. Particle Size Distribution (PSD) Measurements. The particle size distribution (PSD) of the fine fraction of the aggregate $(<500 \mu \mathrm{m})$, cement, and powdered mixed CRT glass were determined by a Horiba LA950 laser scattering PSD analyser; analyses was made in water after a 3 min sonication; PSD curves are represented with logarithmic abscissa. In order to access the PSD of the aggregate's fine fraction, the total as received product was sieved $(500 \mu \mathrm{m})$ and fines were separated from coarse particles; the fines represent $25 \%$ of the total aggregate.

2.2.3. Materials Composition. The ratio between cement and aggregate quantity (natural aggregate plus glass cullet) was set at $1 / 3$ as this is a frequently used ratio. Some reference glass free compositions, hereafter called $\mathrm{R}$, containing cement, aggregate, superplasticizer, and an optimized amount of water were also prepared as blank samples in order to compare the mechanical behaviour, after hydration, of the materials produced, bearing in mind that the focus of the present research regards the production of materials obtained by replacing part of the natural aggregate with an equivalent mass of 5, 10, and $20 \mathrm{wt} \%$ of milled and sieved glass powder from mixed CRT glass. Samples with symbolic names, corresponding aggregate composition, s/c, and water/cement (w/c) ratios are reported in Table 2.

2.2.4. Materials Preparation. For the mixture preparation and w/c optimization, a $5 \mathrm{~L}$ Hobart planetary conforming to ASTM C305 standards was used. The optimized amount of water was determined by the ASTM C1437 slump test performed on the reference blend $\mathrm{R}$. The paste is said to have the right workability if the cake width is $200( \pm 20) \mathrm{mm}$. The identified optimal w/c value of the reference blend (R) was 0.44 ; this same value was applied to all the superplasticizer free compositions. Blends containing superplasticizer required reduced amounts of water as displayed in Table 2. Pastes were then poured under vibration into moulds with dimensions of $100 \times 100 \times 100 \mathrm{~mm}$, sealed with a plastic film to ensure mass curing and aged $24 \mathrm{~h}$ for a first hydration. Samples were then demoulded, sealed again with a plastic
TABLE 2: Specimens symbolic names, corresponding aggregate composition, superplasticizer/cement (s/c) and water cement (w/c) ratios.

\begin{tabular}{lcccc}
\hline Sample & $\begin{array}{c}\text { Natural aggregate } \\
(\text { wt } \%)\end{array}$ & $\begin{array}{c}\text { CRT glass } \\
(\mathrm{wt} \%)\end{array}$ & $\begin{array}{c}\text { s/c } \\
(\%)\end{array}$ & $\mathrm{w} / \mathrm{c}$ \\
\hline R & 100 & 0 & 0 & 0.44 \\
R1 & 100 & 0 & 1 & 0.31 \\
R2 & 100 & 0 & 2 & 0.27 \\
V5 & 95 & 5 & 0 & 0.44 \\
V51 & 95 & 5 & 1 & 0.31 \\
V52 & 95 & 5 & 2 & 0.27 \\
V10 & 90 & 10 & 0 & 0.44 \\
V101 & 90 & 10 & 1 & 0.31 \\
V102 & 90 & 10 & 2 & 0.27 \\
V20 & 80 & 20 & 0 & 0.44 \\
V201 & 80 & 20 & 1 & 0.31 \\
V202 & 80 & 20 & 2 & 0.27 \\
\hline
\end{tabular}

film, and cured again in the air for $24 \mathrm{~h}$ and then in water at room temperature for $3,7,28,90$, and $180 \mathrm{~d}$. The ageing water was maintained at the constant temperature of $25^{\circ} \mathrm{C}$ $\left( \pm 3^{\circ} \mathrm{C}\right)$ and replaced with fresh water every $3 \mathrm{~d}$ of curing. After curing, before their characterisation, samples were dried with a cloth and aged in the atmosphere for $24 \mathrm{~h}$. Specimens used for release evaluation were not aged in water but sealed with a plastic film for $7 \mathrm{~d}$ and then tested.

2.2.5. Materials Characterization. Compression tests were performed after 3, 7, 28, 90, and $180 \mathrm{~d}$ in accordance with the ASTM C469 norm using Shimadzu AG10 apparatus; data were averaged over 5 measurements. Expansion was measured by a calliper after $28 \mathrm{~d}$ of curing in water. Fracture surfaces were examined by an Assing EVO40 Scanning Electron Microscope (SEM) coupled with the Energy Dispersive X-ray Spectroscopy (EDXS). The ASTM C642 norm was used to test the water absorption of the samples after curing for the established number of days.

2.2.6. Leaching Evaluation. After ageing for $7 \mathrm{~d}$, the $\mathrm{R}$ and V20 samples were submitted to an elution release test in water. V20 was selected in order to test a composition containing the highest amount of mixed CRT glass and displaying a high level of water absorption. For this measurement, the above specimens were aged in an autoclave, at $120^{\circ} \mathrm{C}$, and $2 \mathrm{kPa}$ for $1 \mathrm{~h}$ using $4 \mathrm{~L}$ of water. After boiling, samples were cooled down to room temperature (in water). The solutions (water plus several salts eluted from the samples weight ratio between mortar sample and solution is around 0.17) were submitted to the ICP tests. For comparison, materials aged in water for $28 \mathrm{~d}$ and used for testing the mechanical strength were submitted to the $\mathrm{Pb}$ release which was determined according to the US EPA 1311 TCLP test which establishes to crush the hydrated mortar $(28 \mathrm{~d})$, sieve the product through a $10 \mathrm{~mm}$ sieve, and extract a solution using glacial acetic acid. 


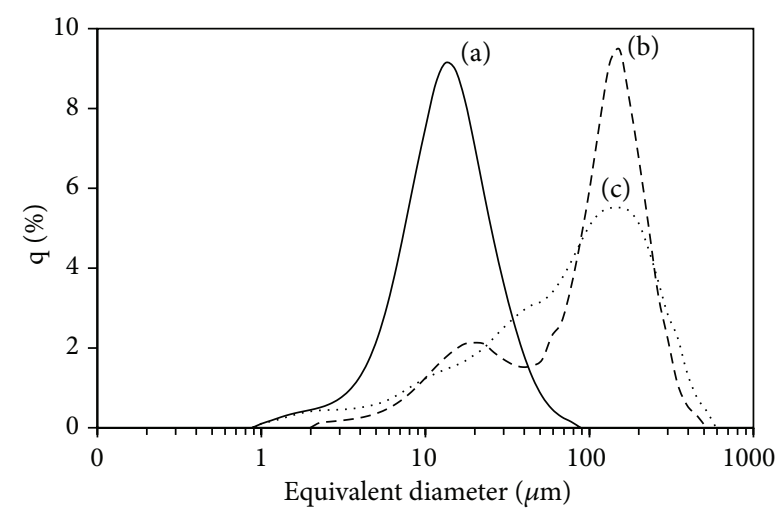

FIGURE 1: PSD curves of the OPC (a), the fine fraction of aggregate (b), and that of the milled and sieved mixed CRT glass used for samples preparation (c).

\section{Results and Discussion}

The starting materials have different particle size distribution: the OPC displays a monomodal distribution of particles with maximum concentration at $12 \mu \mathrm{m}$ (see Figure 1); milled and sieved CRT glass has a broad PSD with a very large peak at around $180 \mu \mathrm{m}$, therefore showing the presence of about $60 \mathrm{vol} \%$ of coarse particles with size greater than $75 \mu \mathrm{m}$ and around $40 \mathrm{vol} \%$ of fines with size below $75 \mu \mathrm{m}$; the fine fraction of the natural aggregate displays a bimodal distribution of particles with two peaks: one, low at $11 \mu \mathrm{m}$, the other, higher, at around $130 \mu \mathrm{m}$. It is known that the most reactive fraction of a component is its finest fraction, which also affects the w/c ratio as well as the alkali silica reaction in the presence of $\mathrm{Na}_{2} \mathrm{O}$ and $\mathrm{K}_{2} \mathrm{O}$. In this contest, we have considered it important to show that the fine fraction of the milled waste glass falls in the range of submicronic sized particles and is overlapped to that of the smallest cement particles. Also natural aggregate contains small particles, the amount of alkalis is very low, and their size is always greater than $2 \mu \mathrm{m}$. It therefore appears reasonable that waste glass particles with size below $1 \mu \mathrm{m}$ could easily interact with cement particles of the same dimension developing pozzolanic activity, limiting ASR, and improving long term properties of the resulting materials. Conversely, small sized particles also influence $\mathrm{w} / \mathrm{c}$ ratio reducing, in this way, mortars workability. However, the absolute amount of glass fines is limited so that their influence on the fresh mortars workability as well as on the properties of the resulting hydrated materials is expected to be limited.

Figures 2(a), 2(b) and 2(c) show the trend, displayed as a function of curing time, of compressive strength (solid lines, left axis) and water absorption (dashed lines, right axis) of three sets of materials, respectively: (a) superplasticizer free, (b) with an $s$ content of $1 \%$, and (c) with an $s$ amount of $2 \%$. Error bars are, for clarity, not displayed due to their overlapping and the possible confusion on reading; however data scattering is, for each composition, maintained within the interval $\pm 5 \%$ of the reported average value. Figure $2(a)$ shows that the average compressive strength of the reference
$\mathrm{R}$ reaches $50 \mathrm{MPa}$ after $3 \mathrm{~d}$ of curing, 66 after 7, 87 after 28, and 97 after 90 and rises to 100 after $180 \mathrm{~d}$; the corresponding water absorption is $6.3 \%$ after $3 \mathrm{~d}$ of curing, 5.7 after 7 , and 5.4 after 28 and lowers to 5.1 and 4.9 after 90 and $180 \mathrm{~d}$, respectively. Such an abnormally high compressive strength is reasonably due to the high strength, low porosity (low water absorption), and chemical nature of the aggregate used in the present research [21]. Compressive strength of composition V10 raises from $45 \mathrm{MPa}$ after $3 \mathrm{~d}$ of curing to 60 after 7, 83 after 28, 100 after 90, and 105 after $180 \mathrm{~d}$; water absorption ranges from 7.1 (3) to $4.4 \%$ (180). It can be observed that compositions V5 and V20 show compressive strength curves below that of the reference material over the whole range of time, whereas that of composition V10 intercepts it between 28 and $90 \mathrm{~d}$ of curing, the final strength being higher than that of R; the addition of CRT glass improves its long-term strength which is little affected by the possible ASR.

In fact, Chen et al. demonstrated that E-glass particle can be used as partial fine aggregate replacement material as well as supplementary binding material depending on its particle size. Particles with size smaller than $75 \mu \mathrm{m}$ could possess cementitious capability resulting from hydration or pozzolanic reaction; the coarser cylindrical might act as a potential crack arrester and inhibits the internal crack propagation [14]. Such behaviour has been confirmed by other authors [13] who demonstrated that ground waste glass containing high amount of alkali could display good performances against ASR if the fraction of fine particles can compensate the high quantity of $\mathrm{Na}_{2} \mathrm{O}+\mathrm{K}_{2} \mathrm{O}$.

Figure 2(b) shows that the addition of $1 \%$ superplasticizer improves compressive strength of all compositions at any ageing time. The strength of composition R1 increases from $80 \mathrm{MPa}$ after $3 \mathrm{~d}$ of curing to 94 after 7, 114 after 28, 120 after 90, and $122 \mathrm{MPa}$ after $180 \mathrm{~d}$. Conversely, compositions containing 5,10 , and $20 \%$ of glass have lower strength than the reference for ageing times lower than $28 \mathrm{~d}$, but their values improve faster being higher than $\mathrm{R} 1$ after $90 \mathrm{~d}$ or more. It must be also pointed out that the curve of composition V101 intercepts that of R1 shortly after $28 \mathrm{~d}$ and displays the best long time mechanical performance whereas those of V51 and V201 cross R after longer ageing times. Data obtained from water absorption tests (also displayed in Figure 2(b)) are in agreement with the corresponding compressive strength data, being low in materials with high strength and high in those having reduced strength levels. More in detail, it can be observed that materials with composition R1 display values between $4.7 \%$ (after $3 \mathrm{~d}$ of curing) and 3.1\% (after $180 \mathrm{~d}$ ) whereas these with V101 between 5.3 (after $3 \mathrm{~d}$ ) and 2.1\% (after $180 \mathrm{~d})$.

Due to the irregular particle shape, blends containing glass had similar but not the same rheological behaviour as the reference compositions. Pastes workability was determined by the slump test, and pastes were defined of right workability when cake width fell into the range of $200 \pm$ $20 \mathrm{~mm}$. However, pastes containing 10 or $20 \mathrm{wt} \%$ of glass gave slump cakes with size close to the inferior limit, being the corresponding slurries of relatively lower fluidity with respect to the reference compositions, in agreement with the results obtained by other authors $[13,14]$, and the resulting 


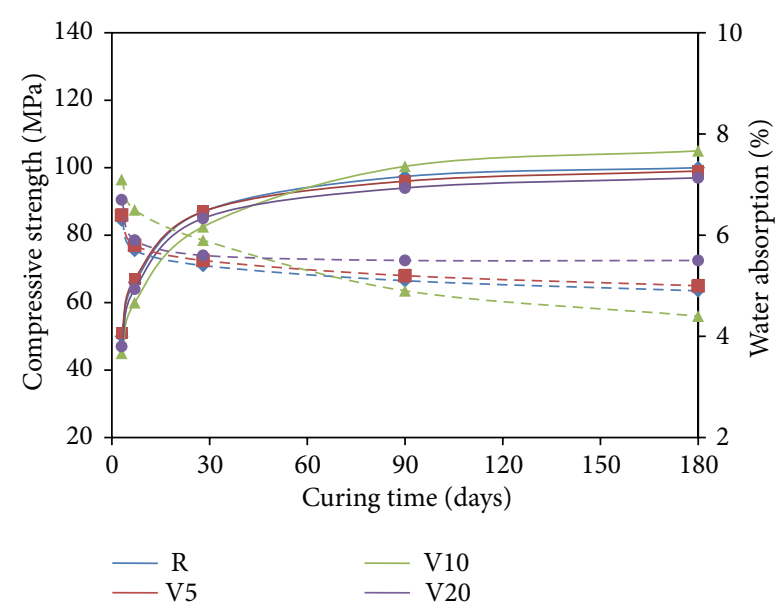

(a)

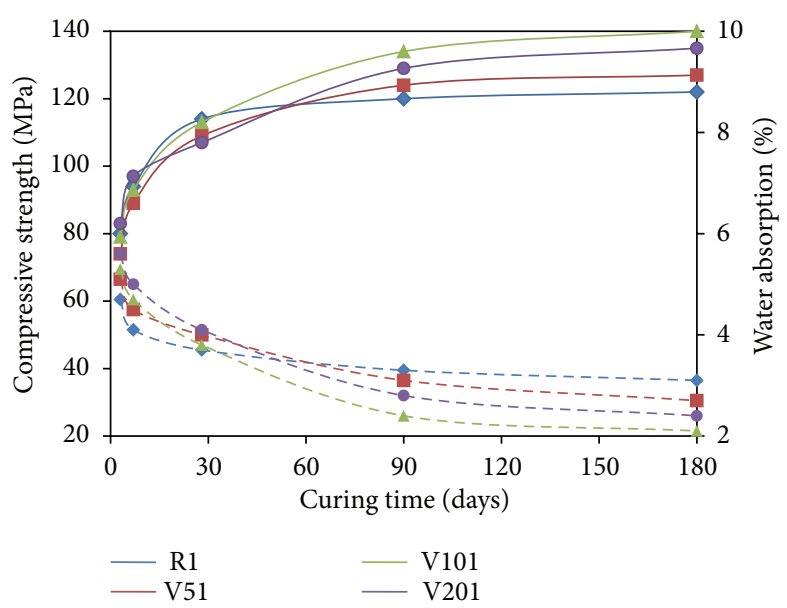

(b)

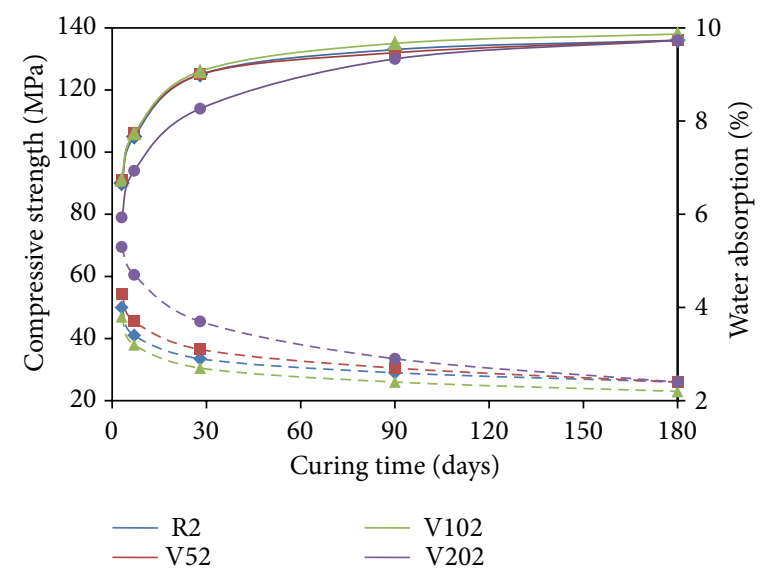

(c)

Figure 2: Trend, displayed as a function of curing time, of compressive strength (solid lines, left axis) and water absorption (dashed lines, right axis) of three sets of materials: (a) superplasticizer free; (b) with a superplasticizer content of 1\%; (c) with superplasticizer content of $2 \%$. Error bars are, for clarity, not displayed due to their overlapping and the possible confusion on reading.

hydrated materials showed a slightly higher residual porosity. The addition of superplasticizer, by improving workability, has a beneficial effect on rheological behaviour and also on the final residual porosity of compositions containing 10 or $20 \mathrm{wt} \%$ of waste glass.

Figure 2(c) reports the curves obtained after testing materials with $2 \%$ of superplasticizer. Compositions R2, V52, and V102 have the same strength after $28 \mathrm{~d}$ and similar strength trend, whereas V202 displays a lower $28 \mathrm{~d}$ strength, but a faster increase; the $180 \mathrm{~d}$ strength of all compositions are concentrated around $137 \mathrm{MPa}$. Also in this set of materials, data obtained from water absorption tests (also displayed in Figure 2(c)) are in line with the corresponding compressive strength levels. In detail, data obtained after $3 \mathrm{~d}$ of curing range from 5.3 for composition V202 to 3.8 for V102, whereas those acquired after $180 \mathrm{~d}$ are all around 2.3\%; intermediate curing times give rise to materials with intermediate water absorption levels.

It must be pointed out that water absorption is not porosity but is related to the open porosity. It means that a body contains not only open porosity but also closed porosity. The water absorption test provides access to the open but not to the closed porosity which remains undetermined together with materials total porosity. However, we would like to point out the strict relationship between compressive strength and water absorption data so that their trend helps to explain material's behaviour.

XRD analysis of the hydrated samples acquired after 28, 90 , and $180 \mathrm{~d}$ did not reveal substantial differences between reference compositions and mixed CRT glass containing materials. For comparison, the present article reports (see Figure 3) the patterns acquired on samples R1 and V201, which have a wide difference of composition and compressive strength after 90 or more days of curing. Patterns are similar, and the same phases can be identified in both materials, that is, portlandite, $\mathrm{Ca}\left(\mathrm{Mg}_{0.67} \mathrm{Fe}_{0.33}\right)\left(\mathrm{CO}_{3}\right)_{2}$, calcite, and quartz. The presence of hydrated phases is not documented by this type of investigation probably due to their amorphous or cryptocrystalline nature $[20,22,23]$. However, it is possible to emphasize the presence of three small peaks which clearly 


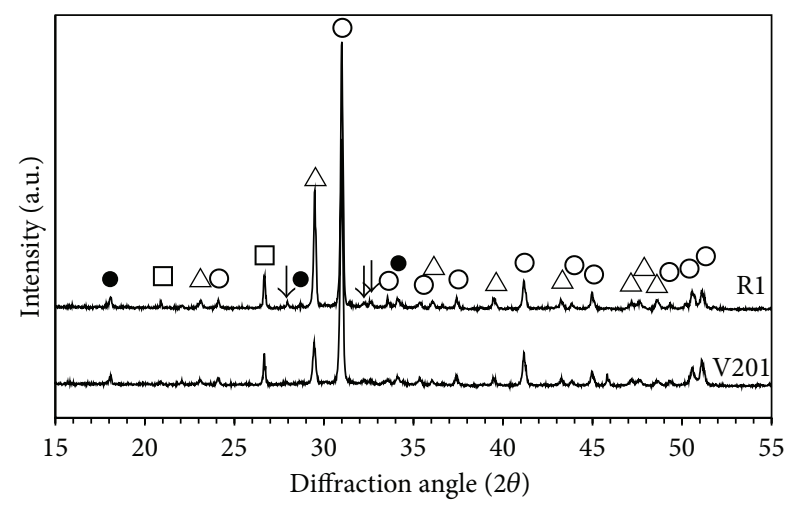

FIgURE 3: X-ray diffraction patterns between 15 and $55^{\circ}$ of the compositions $\mathrm{R} 1$ and V201. The phases are identified by the following symbols: (๑) portlandite; (O) $\mathrm{Ca}\left(\mathrm{Mg}_{0.67} \mathrm{Fe}_{0.33}\right)\left(\mathrm{CO}_{3}\right)_{2} ;(\triangle)$ calcite; ( $\square$ ) quartz; peaks due to residual calcium silicates compounds are highlighted by arrows.

appear in R and not in V201; in Figure 3 they are indicated by an arrow and may be attributed to the presence of residual calcium silicates. One could be led to infer that, in $\mathrm{R}$, this phase is still present after $90 \mathrm{~d}$, whereas in V201 it is almost completely consumed, thanks to the presence of the glass small particles.

The different mechanical behaviour of glass containing materials with respect to the reference glass free compositions may, moreover, be explained by the contribution to the hydration phenomena of the glass particles during mortar curing; such information could be supplied by SEM investigation, but it is necessary to start from the assumption that the coarse glass particles should contribute in a different mode with respect to the smaller ones. The SEM analysis has been made over all the samples, considering ageing time coupled with materials composition, but for brevity, only the most representative images have been reported in the present paper. Figure 4(a) shows a SEM image of the fracture surface of a sample with composition V201 after $90 \mathrm{~d}$ of curing. It is possible to observe that the large glass particle (dark) is strictly entrapped by the cementitious matrix; the interface appears well defined with no voids. The EDXS analysis of the particles showed that the glass mainly contains $\mathrm{SiO}_{2}$ and $\mathrm{BaO}$, but $\mathrm{Na}_{2} \mathrm{O}, \mathrm{K}_{2} \mathrm{O}$, and $\mathrm{Al}_{2} \mathrm{O}_{3}$ are also present; the cementitious zone mainly contains $\mathrm{CaO}$ accompanied by smaller amounts of $\mathrm{SiO}_{2}, \mathrm{MgO}, \mathrm{Al}_{2} \mathrm{O}_{3}$, and $\mathrm{Fe}_{2} \mathrm{O}_{3}$. It is also possible to speculate the development of a hypothetic hydrated phase containing $\mathrm{SiO}_{2}$ (10 wt\%), $\mathrm{CaO}(38 \%), \mathrm{CO}_{2}$ (40\%), $\mathrm{Al}_{2} \mathrm{O}_{3}$ (3.5\%), and $\mathrm{BaO}(5 \%)$ since EDXS analysis of this composition has revealed a small lump which appears well stuck to the large glass particle and is highlighted by an arrow. This hypothesis is, however, not confirmed by other investigations and, at this point, must be considered speculative.

The effect of small glass particles on the materials microstructure can be observed in Figure 4(b) where the presence of well-developed silicate hydrated crystal clusters are visible $[10,11,18,24]$. The EDXS analysis revealed that smooth particles are CRT glass with compositions $\mathrm{SiO}_{2}$ (62.9 wt\%), $\mathrm{CaO}$ (1.5\%), $\mathrm{PbO}$ (6.7\%), $\mathrm{Al}_{2} \mathrm{O}_{3}$ (1.3\%), $\mathrm{Na}_{2} \mathrm{O}$ (5.4\%), $\mathrm{K}_{2} \mathrm{O}(6.2 \%)$, and $\mathrm{BaO}(16 \%)$ whereas the surrounding matrix and elongated crystals were detected as containing, respectively, $\mathrm{SiO}_{2}$ (19.4 mol\%), $\mathrm{CaO}(61.4 \%), \mathrm{MgO}(1 \%)$, $\mathrm{Al}_{2} \mathrm{O}_{3}$ (3.2\%), $\mathrm{K}_{2} \mathrm{O}$ (8.7\%), $\mathrm{Fe}_{2} \mathrm{O}_{3}$ (6.3\%), $\mathrm{SiO}_{2}$ (37.2\%), $\mathrm{CaO}(58.4 \%), \mathrm{MgO}(1.7 \%)$, and $\mathrm{Al}_{2} \mathrm{O}_{3}$ (2.7\%). Such welldeveloped silicate hydrated crystal clusters were observed only around the small glass particles and not in the reference samples thus confirming that particles with size smaller than $75 \mu \mathrm{m}$ could possess cementitious capability resulting from hydration or pozzolanic reaction concurring to limit ASR. As a consequence, provided that curing time is sufficient, the inevitable pores which are formed in the c/a matrix during mortar production may be filled with silicate hydrated crystals with a high shape ratio which interlock the surrounding material promoting the development of densely packed structures, raising compressive strength and reducing materials' permeability.

Materials aged for $180 \mathrm{~d}$ were also submitted to thermo gravimetric analysis (TGA) which did not supply any further information about the different behaviour between reference and glass containing compositions; consequently, TGA graphics are not specified in the present communication. It can also be pointed out that after $28 \mathrm{~d}$ of exposure to a moist environment, the change in length of the samples is always below the normally accepted value of $0.05 \%$ suggested in ASTM C33.

The ICP analysis made on the solutions obtained from the release tests in water of samples R and V20 is displayed in Table 3 which shows, in accordance with the work of other researchers, low elution of hazardous elements from the mortar samples containing waste materials [25]. In Table 3, only data resulted from samples containing the highest amount of mixed CRT glass and a high level of water absorption are reported since all the other compositions showed lower quantities of released hazardous elements. Some elements, such as $\mathrm{Ca}, \mathrm{K}, \mathrm{Na}$, and $\mathrm{S}$ are, conversely, present in non negligible amounts, but their presence is not considered a warning parameter by most of the standard release tests. The elution release test used in the present study is not a codified test, as presently is not established leaching test for mortars or concretes containing hazardous elements, but it is indicative of the possible environmental compatibility of the materials produced. However, for safety, the $\mathrm{Pb}$ and Ba release from materials with composition V20 aged $28 \mathrm{~d}$ was also accessed by the TCLP test which showed 2.40 and $1.85 \mathrm{mg} \mathrm{L}^{-1}$, respectively, which are far from the established limits of 5 and $100 \mathrm{mg} \mathrm{L}^{-1}$, respectively, and in sufficiently good agreement with data reported by other authors [15-17]. It must be finally pointed out that TCLP tests are mandatory when hazardous waste materials need to be managed or disposed of to landfill, but equivalent tests on industrial products containing the same waste are presently missing. The authors of the present research therefore suggest the development of standards leaching tests to be used with monolithic materials containing waste hazardous components (i.e., ASTM or others for mortars or concretes). 


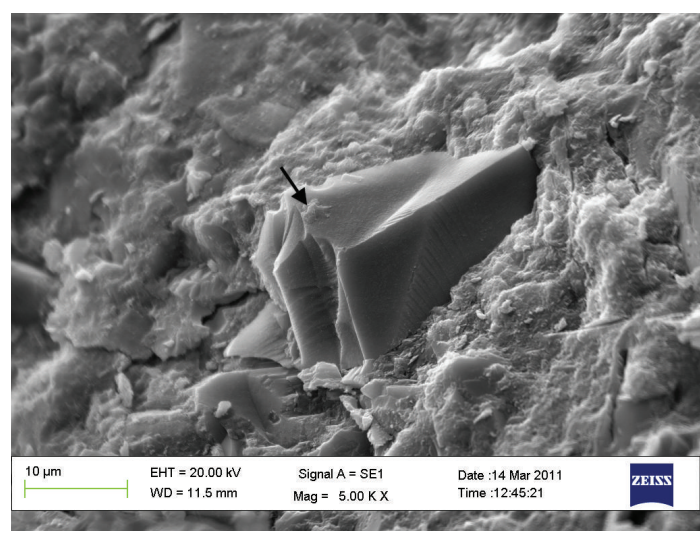

(a)

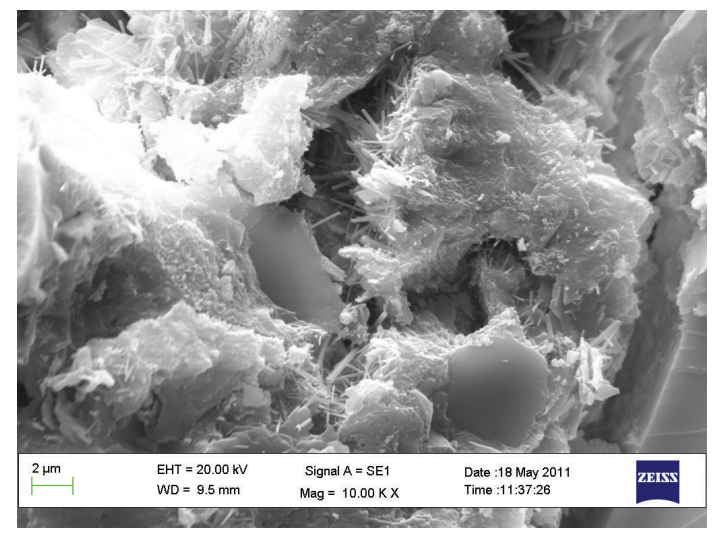

(b)

FIGURE 4: SEM micrographs showing the fracture surface of a sample with composition V201 after $90 \mathrm{~d}$ of curing. (a) a great glass particle (dark) is strictly entrapped by the cementitious matrix: the interface appears well defined with no voids; (b) the presence of small glass particles leads to the development of long hydrated silicates crystals.

TABLE 3: More abundant elements $\left(\mu \mathrm{g} \mathrm{Kg}^{-1}=\right.$ parts per billion) revealed by the ICP on the solutions obtained from the water absorption test of samples with composition R and V20. Elements not reported were determined in quantity lower than $25 \mathrm{ppb}$.

\begin{tabular}{lccccccccccc}
\hline Sample name & $\mathrm{Mg}$ & $\mathrm{Al}$ & $\mathrm{Ca}$ & $\mathrm{Si}$ & $\mathrm{Na}$ & $\mathrm{K}$ & $\mathrm{Fe}$ & $\mathrm{Ba}$ & $\mathrm{Sr}$ & $\mathrm{Pb}$ & $\mathrm{S}$ \\
\hline $\mathrm{R}$ & 2311 & 3100 & 22005 & 786 & 16420 & 11003 & 417 & $<25$ & 114 & $<25$ & 19990 \\
$\mathrm{~V} 20$ & 3409 & 3333 & 16871 & 3956 & 20097 & 16294 & 390 & 727 & 326 & 799 & 21388 \\
\hline
\end{tabular}

\section{Conclusions}

In the present research, the production of stable mortars was carried out using a commercial OPC, ground waste CRT glass, natural aggregate, and water; the addition of superplasticizer was also investigated. Mortars were produced using a fixed c/a ratio (1/3), whereas milled CRT glass was added in different proportions as well as an amount of superplasticizer.

The following important conclusions were derived from the study.

(1) All hydrated materials displayed high compression strength after $3,7,28,90$, and $180 \mathrm{~d}$ of curing in a moist environment.

(2) Glass containing samples showed a more rapid increase of strength with respect to the reference compositions when subjected to long-term ageing.

(3) Materials with a s/c ratio of 1 showed the best overall behaviour.

(4) The addition of more than $10 \mathrm{wt} \%$ of CRT glass powder did not lead to the production of materials with the best mechanical performances.

(5) The results obtained in the present research are reasonably due to the favourable influence of the small glass particles which interact with the hydraulic phases promoting pozzolanic reaction, limiting ASR and increasing the amount of hydrated silicates produced during long term ageing.

(6) The ICP analysis made on the solutions obtained from the release tests in water confirms the low elution of hazardous elements from the materials produced and therefore their possible environmental compatibility.

\section{References}

[1] C. Lee and C. Hsi, "Recycling of scrap cathode ray tubes," Environmental Science and Technology, vol. 36, no. 1, pp. 69-75, 2002.

[2] S. Mostaghel and C. Samuelsson, "Metallurgical use of glass fractions from waste electric and electronic equipment (WEEE)," Waste Management, vol. 30, no. 1, pp. 140-144, 2010.

[3] F. Andreola, L. Barbieri, A. Corradi, and I. Lancellotti, "Cathode ray tube glass recycling: an example of clean technology," Waste Management and Research, vol. 23, no. 4, pp. 314-321, 2005.

[4] F. Andreola, L. Barbieri, E. Karamanova, I. Lancellotti, and M. Pelino, "Recycling of CRT panel glass as fluxing agent in the porcelain stoneware tile production," Ceramics International, vol. 34, no. 5, pp. 1289-1295, 2008.

[5] A. M. Neville and J. J. Brooks, Concrete Technology, Longman, London, UK, 1990.

[6] M. N. Haque, "Strength development and drying shrinkage of high-strength concretes," Cement and Concrete Composites, vol. 18, no. 5, pp. 333-342, 1996.

[7] C. Polley, S. M. Cramer, and R. V. De La Cruz, "Potential for using waste glass in portland cement concrete," Journal of Materials in Civil Engineering, vol. 10, no. 4, pp. 210-219, 1998.

[8] R. Dhir, T. Dyer, A. Tang, and Y. Cui, "Towards maximising the value and sustainable use of glass," Concrete, vol. 38, no. 1, pp. 38-40, 2004.

[9] E. A. Byars, B. Morales-Hernandez, and Z. HuiYing, "Waste glass as concrete aggregate and pozzolan Laboratory and industrial projects," Concrete, vol. 38, no. 1, pp. 41-44, 2004. 
[10] V. Corinaldesi, G. Gnappi, G. Moriconi, and A. Montenero, "Reuse of ground waste glass as aggregate for mortars," Waste Management, vol. 25, no. 2, pp. 197-201, 2005.

[11] I. B. Topçu and M. Canbaz, "Properties of concrete containing waste glass," Cement and Concrete Research, vol. 34, no. 2, pp. 267-274, 2004.

[12] V. Ducman, A. Mladenovič, and J. S. Šuput, "Lightweight aggregate based on waste glass and its alkali-silica reactivity," Cement and Concrete Research, vol. 32, no. 2, pp. 223-226, 2002.

[13] A. Saccani and M. C. Bignozzi, "ASR expansion behavior of recycled glass fine aggregates in concrete," Cement and Concrete Research, vol. 40, no. 4, pp. 531-536, 2010.

[14] C. H. Chen, R. Huang, J. K. Wu, and C. C. Yang, "Waste E-glass particles used in cementitious mixtures," Cement and Concrete Research, vol. 36, no. 3, pp. 449-456, 2006.

[15] D. Kim, M. Quinlan, and T. F. Yen, "Encapsulation of lead from hazardous CRT glass wastes using biopolymer cross-linked concrete systems," Waste Management, vol. 29, no. 1, pp. 321$328,2009$.

[16] T. Ling and C. Poon, "A comparative study on the feasible use of recycled beverage and CRT funnel glass as fine aggregate in cement mortar," Journal of Cleaner Production, vol. 29-30, pp. 46-52, 2012.

[17] T.-C. Ling and C.-S. Poon, "Feasible use of recycled CRT funnel glass as heavyweight fine aggregate in barite concrete," Journal of Cleaner Production, vol. 33, pp. 42-49, 2012.

[18] J. Péra, S. Husson, and B. Guilhot, "Influence of finely ground limestone on cement hydration," Cement and Concrete Composites, vol. 21, no. 2, pp. 99-105, 1999.

[19] H. Qasrawi, F. Shalabi, and I. Asi, "Use of low $\mathrm{CaO}$ unprocessed steel slag in concrete as fine aggregate," Construction and Building Materials, vol. 23, no. 2, pp. 1118-1125, 2009.

[20] M. Collepardi, Scienza e Tecnologia del Calcestruzzo, Hoepli, Milan, Italy, 3rd edition, 1991.

[21] M. Husem, "The effects of bond strengths between lightweight and ordinary aggregate-mortar, aggregate-cement paste on the mechanical properties of concrete," Materials Science and Engineering A, vol. 363, no. 1-2, pp. 152-158, 2003.

[22] N. F. W. Taylor, Cement Chemistry, Thomas Telford, London, UK, 2nd edition, 1997.

[23] P. C. Hewlett, Lea's Chemistry of Cement and Concrete, Arnorld, London, UK, 4th edition, 1998.

[24] C. Shi and K. Zheng, "A review on the use of waste glasses in the production of cement and concrete," Resources Conservation and Recycling, vol. 52, pp. 234-247, 2007.

[25] R. Siddique, "Use of municipal solid waste ash in concrete," Resources, Conservation and Recycling, vol. 55, no. 2, pp. 83-91, 2010. 

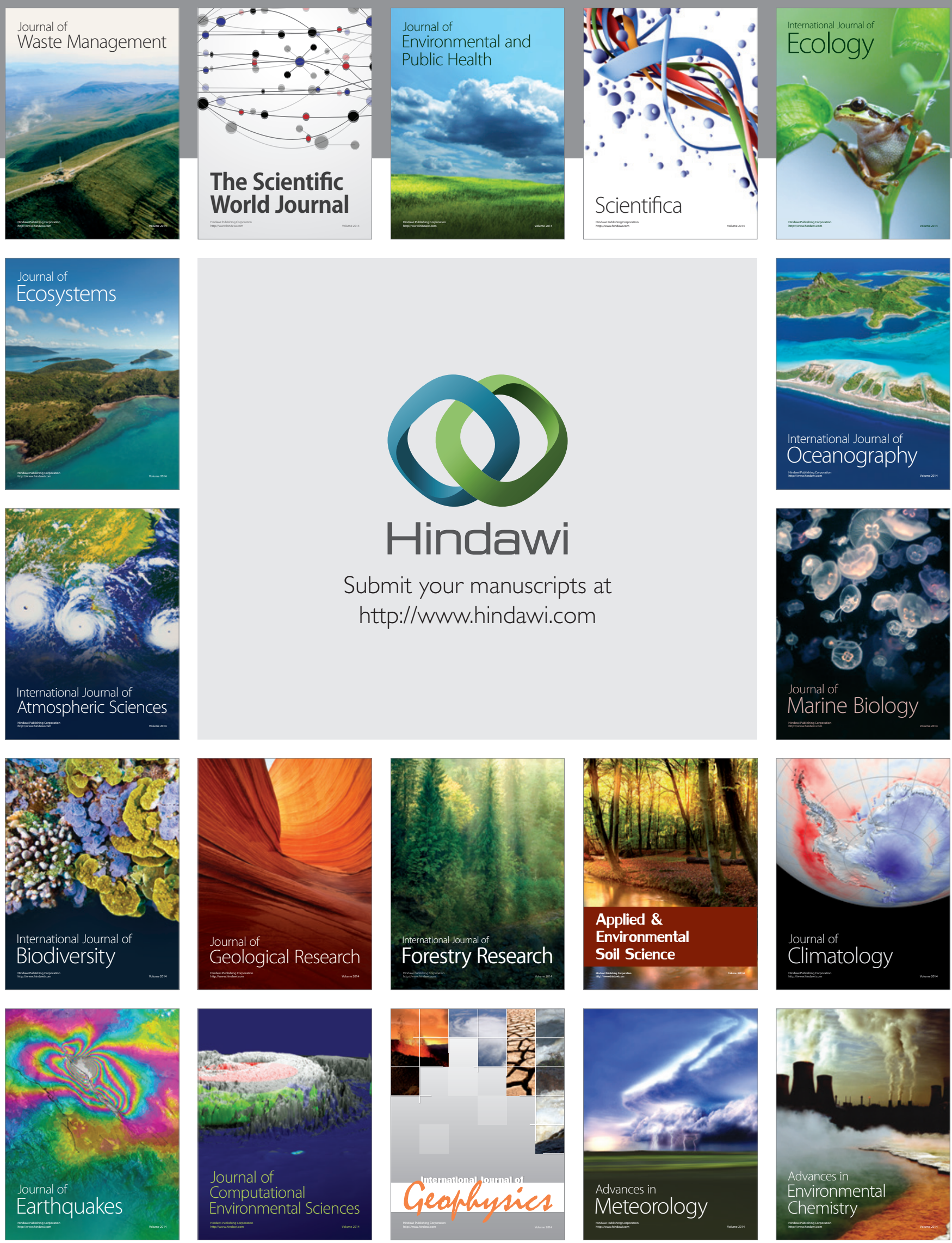